\title{
Low Vital Capacity is Associated with Diabetes Despite Inverse Relationships with Metabolic Risk Factors in Lean Japanese Men
}

\author{
Eiji Oda and Ryu Kawai
}

\begin{abstract}
Background There is no study examining the relationships between vital capacity and diabetes or metabolic risk factors in lean subjects.

Methods Cross-sectional relationships between \% vital capacity (\%VC) and diabetes and metabolic risk factors were examined in Japanese subjects using medical check-up data from 2,079 men and 1,215 women. Subjects were divided into lean (BMI $<23 \mathrm{~kg} / \mathrm{m}^{2}$ ) and obese (BMI $\geq 23 \mathrm{~kg} / \mathrm{m}^{2}$ ) groups and then subdivided into lower \% VC $(\leq 95 \%)$ and higher \%VC $(\geq 96 \%)$ subgroups by gender. Metabolic risk factors and prevalence of diabetes and MS were compared between the subjects in each group, and then excluding current smokers and between subjects with the lowest quartile of $\% \mathrm{VC}$ and those with the highest quartile of $\% \mathrm{VC}$ in the lean men group. Spearman's correlation coefficients between $\% \mathrm{VC}$ and metabolic risk factors were calculated separately in obese subjects and in lean subjects by gender.

Results The prevalence of diabetes, but not metabolic syndrome, was significantly higher in subjects with the lower \% VC than in those with the higher \% VC in the lean men despite the fact that age, obesity parameters, systolic and diastolic blood pressures were significantly lower in subjects with the lower \% VC than in those with the higher $\% \mathrm{VC}$ and triglycerides, high-density lipoprotein cholesterol, high-sensitivity C-reactive protein, white blood cell count, and heart rate were not significantly different between the two groups.

Conclusion Low vital capacity was significantly associated with diabetes in lean Japanese men despite inverse relationships with metabolic risk factors.
\end{abstract}

Key words: vital capacity, diabetes, metabolic syndrome, lean men

(Inter Med 48: 1201-1207, 2009)

(DOI: 10.2169/internalmedicine.48.2085)

\begin{tabular}{l} 
Introduction \\
\hline While low vital capacity was reported as a predictor of \\
insulin resistance or diabetes in Western countries where the \\
prevalence of obesity is high (1-5), there are few reports on \\
the relationship between respiratory function and metabolic \\
syndrome (MS) or diabetes in Japanese where the preva- \\
lence of obesity is very low. We investigated cross-sectional \\
relationships between \% vital capacity (\%VC) and diabetes \\
and MS-related risk factors in lean Japanese men and \\
women.
\end{tabular}

\section{Introduction}

While low vital capacity was reported as a predictor of
insulin resistance or diabetes in Western countries where the
prevalence of obesity is high (1-5), there are few reports on
the relationship between respiratory function and metabolic
syndrome (MS) or diabetes in Japanese where the preva-
lence of obesity is very low. We investigated cross-sectional
relationships between \% vital capacity (\%VC) and diabetes
and MS-related risk factors in lean Japanese men and
women.

Medical Check-up Center, Tachikawa Medical Center, Nagaoka

Received for publication January 22, 2009; Accepted for publication April 6, 2009

Correspondence to Dr. Eiji Oda, ijie@venus.sannet.ne.jp

\begin{tabular}{l} 
Methods \\
\hline Subjects \\
Between April 1 and December 29, 2008, 2,136 men and \\
1,255 women visited our medical check-up center for a na- \\
tionwide general medical check-up program named "Ningen \\
Dock", one of the programs prepared by our Medical \\
Check-up Center. Visitors were all required to fill out a \\
questionnaire prepared by the Ministry of Health, Labor, and \\
Welfare including questions about history of cardiovascular \\
disease, smoking status, antihypertensive and hypoglycemic
\end{tabular}


medication, and alcohol consumption. Among these persons, 13 men and 15 women without signed consent, 11 men and 14 women without respiratory function data, a man and a woman without renal function data, 28 men and 9 women with serum levels of high-sensitivity C-reactive protein (hs$\mathrm{CRP}$ ) higher than $10 \mathrm{mg} / \mathrm{L}$, and 4 men and 1 woman without body fat \% $(\mathrm{BF} \%)$ data were excluded resulting in 2,079 men and 1,215 women. The protocol for the present study was approved by the ethics committee of Tachikawa Medical Center and signed informed consent was obtained from each subject.

\section{Measurements}

After an overnight fast, blood samples were obtained to measure serum levels of routine medical check-up tests. Plasma glucose, serum triglycerides, high-density lipoprotein (HDL) cholesterol, total cholesterol, low-density lipoprotein (LDL) cholesterol, hemoglobin A1c, uric acid, blood cell counts, electrolytes, liver and kidney function tests, and amylase were measured at BML Nagaoka (Nagaoka, Japan) using routine laboratory methods, except for hs-CRP which was measured at BML General Laboratory (Tokyo, Japan) with nephelometry using N-latex CRP-2 (Siemens Healthcare Japan, Tokyo, Japan). The measurement limit of hsCRP was $0.02 \mathrm{mg} / \mathrm{L}$ and the value of hs-CRP less than the measurement limit was considered as $0.01 \mathrm{mg} / \mathrm{L}$. Respiratory function tests including $\% \mathrm{VC}$ and forced expiratory volume in 1 second (FEV1) divided by forced vital capacity (FVC) (FEV1\%) were performed with the Autospirometer System 7 (Minato Medical Science, Osaka, Japan). BF\% was measured with bioelectrical impedance analysis using TBF-210 (TANITA, Tokyo, Japan). Heart rate was automatically recorded by an electrocardiogram with the subjects in a supine position. Average systolic blood pressure (SBP) and diastolic blood pressure (DBP) were calculated from two measurements with the subjects in a sitting position after 5 min rest. Body weight was measured with the subjects wearing lightweight clothing provided by our center and the weight of the clothing was subtracted from the measured body weight. Waist circumference (WC) was measured at the level of the umbilicus. Body mass index (BMI) was calculated as weight in kilograms divided by the square of height in meters. Estimated glomerular filtration rate (eGFR) was calculated as eGFR $\left(\mathrm{mL} / \mathrm{min} / 1.73 \mathrm{~m}^{2}\right)=194 \times$ creatinine $^{-1.094} \times$ age $^{-0.287}$ in men, and $194 \times$ creatinine $^{-1.094} \times$ age $^{-0.287} \times$ 0.739 in women according to the guideline of the Japanese Society of Nephrology.

\section{Data analysis}

Diabetes was defined as fasting plasma glucose levels $\geq$ $126 \mathrm{mg} / \mathrm{dL}$ or those receiving hypoglycemic medication. MS was defined by the revised National Cholesterol Education Program (NCEP) criteria (6) where the cut-off point of WC was modified for Japanese as $\geq 90 \mathrm{~cm}$ in men and $\geq 80 \mathrm{~cm}$ in women according to the recommendation by the International Diabetes Federation (7). Subjects receiving antihyper- tensive or hypoglycemic medication were considered to have the respective MS component. Subjects were divided into a lean $\left(\right.$ BMI $\left.<23 \mathrm{~kg} / \mathrm{m}^{2}\right)$ and an obese $\left(\right.$ BMI $\geq 23 \mathrm{~kg} / \mathrm{m}^{2}$ ) groups by gender, then, subdivided into a lower \%VC $(\leq$ $95 \%)$ and a higher \%VC $(\geq 96 \%)$ subgroups. MS-related risk factors and prevalence of diabetes and MS were compared between subjects with the lower \%VC and those with the higher \%VC separately in the lean group and the obese group, then, compared excluding current smokers in the lean men group. MS-related risk factors and prevalence of diabetes and MS were also compared between subjects with the lowest quartile of \% VC (Q1) and those with the highest quartile of \% VC (Q4) in the lean men. Spearman's correlation coefficients between \% VC and MS-related risk factors were calculated separately in obese subjects and in lean subjects using Dr SPSS-2. P values less than 0.05 were considered to be statistically significant.

\section{Results}

\section{Basal data stratified by BMI}

Basal data stratified by the BMI cut point of $23 \mathrm{~kg} / \mathrm{m}^{2}$ is presented in Table 1. BF\%, WC, SBP, DBP, fasting plasma glucose, triglycerides, hs-CRP, white blood cell count (WBC), gamma glutamyltransferase (GGT), and the prevalence of both diabetes and MS were significantly higher and HDL cholesterol and eGFR were significantly lower in obese subjects than in lean subjects both in men and women. Heart rate was significantly higher in obese subjects than in lean subjects only in men and age was significantly higher and FEV1\% was significantly lower in obese subjects than in lean subjects only in women.

\section{Results in obese subjects}

Data in obese subjects are presented in Table 2. BMI, BF $\%$, WC, SBP, DBP, fasting plasma glucose, triglycerides, hsCRP, WBC, heart rate, FEV1\%, and the prevalence of both diabetes and MS were significantly higher and HDL cholesterol was significantly lower in subjects with the lower \% $\mathrm{VC}$ than in those with the higher \% VC in men. WC, fasting plasma glucose, hs-CRP, WBC, FEV1\%, and the prevalence of both diabetes and MS were significantly higher in subjects with the lower \% VC than in those with the higher \% $\mathrm{VC}$ in women.

\section{Results in lean subjects}

Data in lean subjects are presented in Table 3. Age, BMI, $\mathrm{BF} \%$, WC, SBP, and DBP were significantly lower but FEV $1 \%$ and the prevalence of diabetes were significantly higher in subjects with the lower \% VC than in those with higher \% $\mathrm{VC}$ in men. Age, BMI, BF\%, WC, and fasting plasma glucose were significantly lower and heart rate and FEV1\% were significantly higher in subjects with the lower \%VC than in those with the higher $\% \mathrm{VC}$ in women. The prevalence of diabetes was not significantly different between 
Table 1. Basal Data Stratified by BMI

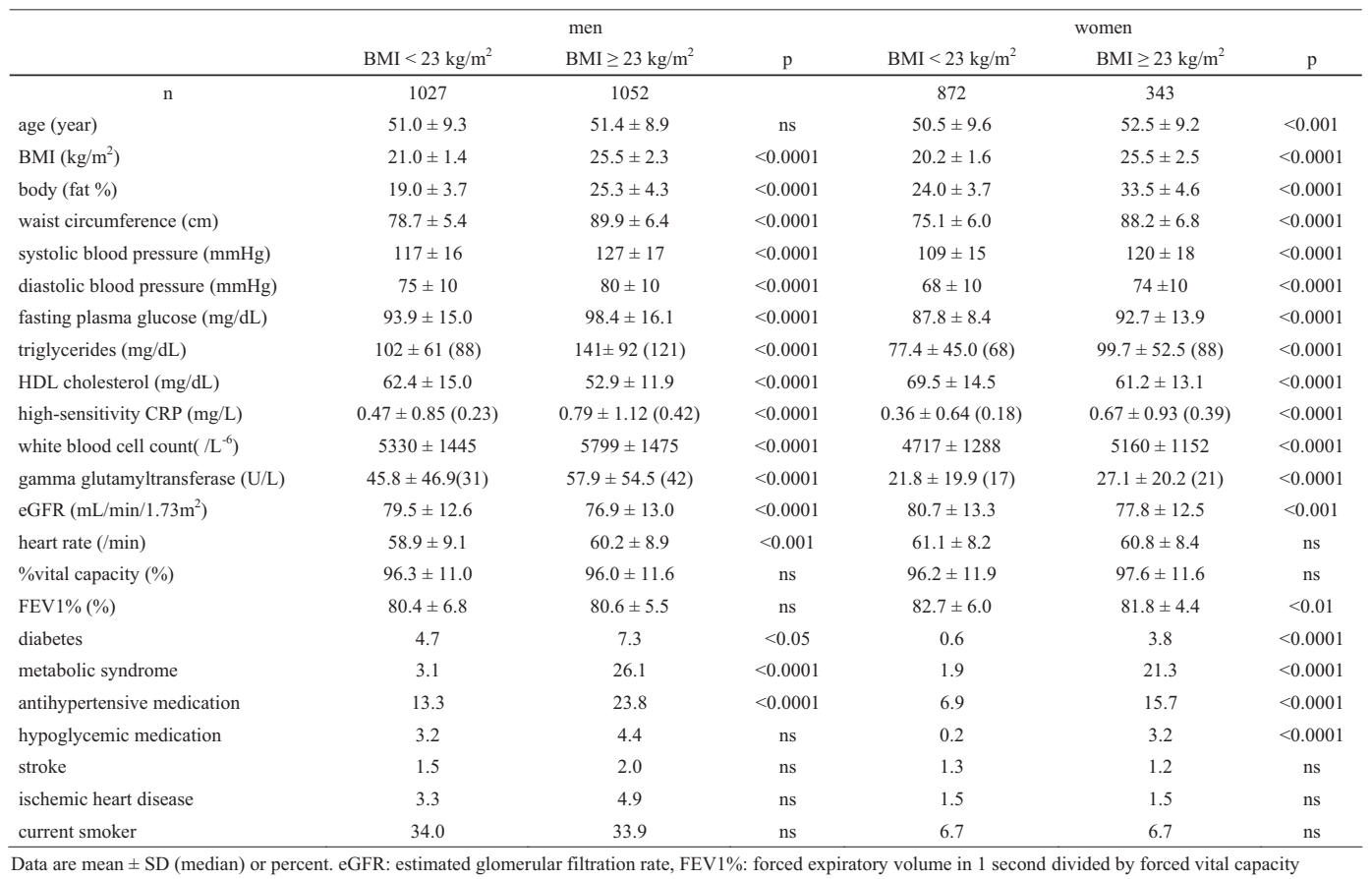

Table 2. Data Stratified by \% Vital Capacity (\%VC) in Subjects with BMI $\geq 23 \mathrm{~kg} / \mathrm{m}^{2}$

\begin{tabular}{|c|c|c|c|c|c|c|}
\hline & \multicolumn{3}{|c|}{ men } & \multicolumn{3}{|c|}{ women } \\
\hline & $\% \mathrm{VC} \leq 95$ & $\% \mathrm{VC} \geq 96$ & $\mathrm{p}$ & $\% \mathrm{VC} \leq 95$ & $\% \mathrm{VC} \geq 96$ & $\mathrm{p}$ \\
\hline $\mathrm{n}$ & 512 & 540 & & 144 & 199 & \\
\hline$\%$ vital capacity $(\%)$ & $86.4 \pm 6.1$ & $105.1 \pm 7.5$ & $<0.0001$ & $86.9 \pm 7.0$ & $105.4 \pm 7.2$ & $<0.0001$ \\
\hline age (year) & $51.5 \pm 9.0$ & $51.3 \pm 8.8$ & $\mathrm{~ns}$ & $53.2 \pm 9.4$ & $52.0 \pm 9.0$ & ns \\
\hline BMI $\left(\mathrm{kg} / \mathrm{m}^{2}\right)$ & $25.9 \pm 2.7$ & $25.1 \pm 1.9$ & $<0.0001$ & $25.6 \pm 2.4$ & $25.4 \pm 2.5$ & ns \\
\hline body (fat \%) & $26.2 \pm 4.5$ & $24.5 \pm 3.9$ & $<0.0001$ & $33.9 \pm 4.6$ & $33.2 \pm 4.6$ & ns \\
\hline waist circumference $(\mathrm{cm})$ & $90.9 \pm 7.0$ & $89.0 \pm 5.7$ & $<0.0001$ & $89.2 \pm 6.5$ & $87.5 \pm 6.9$ & $<0.05$ \\
\hline systolic blood pressure $(\mathrm{mmHg})$ & $128 \pm 17$ & $125 \pm 17$ & $<0.01$ & $121 \pm 18$ & $118 \pm 17$ & $\mathrm{~ns}$ \\
\hline diastolic blood pressure ( $\mathrm{mmHg}$ ) & $81 \pm 11$ & $79 \pm 10$ & $<0.05$ & $75 \pm 11$ & $74 \pm 10$ & ns \\
\hline fasting plasma glucose (mg/dL) & $100.5 \pm 18.5$ & $96.5 \pm 13.2$ & $<0.0001$ & $95.4 \pm 17.3$ & $90.8 \pm 10.5$ & $<0.01$ \\
\hline triglycerides (mg/dL) & $152 \pm 98(131)$ & $131 \pm 84(113)$ & $<0.001$ & $102 \pm 56(93)$ & $98 \pm 50(86)$ & ns \\
\hline HDL cholesterol (mg/dL) & $51.5 \pm 11.6$ & $54.3 \pm 12.0$ & $<0.001$ & $60.5 \pm 12.3$ & $61.7 \pm 13.7$ & $\mathrm{~ns}$ \\
\hline high-sensitivity CRP (mg/L) & $0.91 \pm 1.24(0.50)$ & $0.67 \pm 0.99(0.37)$ & $<0.001$ & $0.85 \pm 1.25(0.49)$ & $0.54 \pm 0.57(0.34)$ & $<0.01$ \\
\hline white blood cell count $\left(/ \mathrm{L}^{-6}\right)$ & $5954 \pm 1525$ & $5652 \pm 1411$ & $<0.001$ & $5379 \pm 1220$ & $5003 \pm 1075$ & $<0.01$ \\
\hline heart rate (/min) & $61.0 \pm 9.1$ & $59.5 \pm 8.7$ & $<0.01$ & $60.6 \pm 8.3$ & $61.0 \pm 8.4$ & $\mathrm{~ns}$ \\
\hline FEV1\%(\%) & $81.4 \pm 5.5$ & $79.8 \pm 5.5$ & $<0.0001$ & $82.4 \pm 4.5$ & $81.3 \pm 4.2$ & $<0.05$ \\
\hline diabetes & 10.5 & 4.3 & $<0.001$ & 6.3 & 2.0 & $<0.05$ \\
\hline metabolic syndrome & 34.0 & 18.7 & $<0.001$ & 28.5 & 16.1 & $<0.01$ \\
\hline antihypertensive medication & 27.9 & 19.8 & $<0.01$ & 22.9 & 10.6 & $<0.01$ \\
\hline hypoglycemic medication & 6.6 & 2.2 & $<0.001$ & 5.6 & 1.5 & $<0.05$ \\
\hline stroke & 2.0 & 2.0 & $\mathrm{~ns}$ & 1.4 & 1.0 & ns \\
\hline ischemic heart disease & 6.4 & 3.5 & $<0.05$ & 2.1 & 1.0 & ns \\
\hline current smoker & 36.9 & 31.1 & $<0.05$ & 6.9 & 6.5 & $\mathrm{~ns}$ \\
\hline
\end{tabular}

subjects with the lower \% VC and those with the higher \% $\mathrm{VC}$ in women. Triglycerides, HDL cholesterol, hs-CRP, WBC, and the prevalence of MS were not significantly different between the two groups both in men and in women.

\section{Detailed analysis in lean men}

Table 4 shows data in lean men excluding current smokers. Age, BMI, BF\%, WC, SBP, DBP, and the prevalence of MS were significantly lower but FEV1\% and the prevalence of diabetes were significantly higher in subjects with the lower \% VC than in those with higher \% VC in nonsmokers.
Table 5 shows data by the quartile of $\% \mathrm{VC}$ in lean men. Age, BMI, BF\%, WC, SBP, and DBP were significantly lower but fasting plasma glucose, FEV1\%, and the prevalence of diabetes were significantly higher in Q1 than in Q4.

Correlations between \%VC and MS-related risk factors in lean subjects and in obese subjects Spearman's correlation coefficients between \% VC and MS-related risk factors are presented in Table 6 separately in the obese and in the lean groups. While BMI, BF\%, WC, SBP, DBP, fasting plasma glucose, triglycerides, hs-CRP, WBC, and GGT were significantly negatively and HDL cholesterol was significantly 
Table 3. Data Stratified by $\%$ Vital Capacity $(\%$ VC) in Subjects with $B M I<23$ kg/m²

\begin{tabular}{|c|c|c|c|c|c|c|}
\hline & \multicolumn{3}{|c|}{ men } & \multicolumn{3}{|c|}{ women } \\
\hline & $\% \mathrm{VC} \leq 95$ & $\% \mathrm{VC} \geq 96$ & $\mathrm{p}$ & $\% \mathrm{VC} \leq 95$ & $\% \mathrm{VC} \geq 96$ & $\mathrm{p}$ \\
\hline $\mathrm{n}$ & 495 & 532 & & 434 & 438 & \\
\hline$\%$ vital capacity (\%) & $87.2 \pm 6.1$ & $104.7 \pm 7.0$ & $<0.0001$ & $86.5 \pm 6.4$ & $105.7 \pm 7.5$ & $<0.0001$ \\
\hline age (year) & $50.2 \pm 9.7$ & $51.9 \pm 8.9$ & $<0.01$ & $49.3 \pm 10.1$ & $51.7 \pm 9.0$ & $<0.001$ \\
\hline BMI $\left(\mathrm{kg} / \mathrm{m}^{2}\right)$ & $20.7 \pm 1.6$ & $21.2 \pm 1.3$ & $<0.0001$ & $19.8 \pm 1.7$ & $20.6 \pm 1.5$ & $<0.0001$ \\
\hline body (fat \%) & $18.6 \pm 3.8$ & $19.3 \pm 3.5$ & $<0.01$ & $23.5 \pm 3.8$ & $24.4 \pm 3.5$ & $<0.001$ \\
\hline waist circumference $(\mathrm{cm})$ & $78.0 \pm 5.7$ & $79.3 \pm 5.1$ & $<0.001$ & $74.2 \pm 6.3$ & $75.9 \pm 5.6$ & $<0.0001$ \\
\hline systolic blood pressure $(\mathrm{mmHg})$ & $116 \pm 17$ & $119 \pm 17$ & $<0.01$ & $108 \pm 16$ & $109 \pm 15$ & ns \\
\hline diastolic blood pressure $(\mathrm{mmHg})$ & $74 \pm 10$ & $76 \pm 10$ & $<0.01$ & $68 \pm 10$ & $68 \pm 9$ & $\mathrm{~ns}$ \\
\hline fasting plasma glucose (mg/dL) & $94.7 \pm 17.4$ & $93.2 \pm 12.2$ & $\mathrm{~ns}$ & $87.2 \pm 8.2$ & $88.3 \pm 8.5$ & $<0.05$ \\
\hline triglycerides (mg/dL) & $101 \pm 57(88)$ & $103 \pm 64(87)$ & $\mathrm{ns}$ & $76.5 \pm 51.6(66)$ & $78 \pm 37(70)$ & $\mathrm{ns}$ \\
\hline HDL cholesterol (mg/dL) & $62.3 \pm 15.7$ & $62.5 \pm 14.3$ & ns & $69.4 \pm 13.8$ & $69.6 \pm 15.1$ & ns \\
\hline high-sensitivity CRP (mg/L) & $0.48 \pm 0.83(0.24)$ & $0.45 \pm 0.87(0.22)$ & ns & $0.39 \pm 0.62(0.20)$ & $0.33 \pm 0.67(0.17)$ & ns \\
\hline white blood cell $\operatorname{count}\left(/ \mathrm{L}^{-6}\right)$ & $5340 \pm 1418$ & $5321 \pm 1471$ & ns & $4735 \pm 1260$ & $4698 \pm 1316$ & ns \\
\hline heart rate $(/ \mathrm{min})$ & $59.2 \pm 9.1$ & $58.6 \pm 9.0$ & $\mathrm{~ns}$ & $61.9 \pm 8.7$ & $60.2 \pm 7.7$ & $<0.01$ \\
\hline FEV1\% $(\%)$ & $81.3 \pm 7.5$ & $79.6 \pm 5.9$ & $<0.0001$ & $83.8 \pm 6.4$ & $81.7 \pm 5.3$ & $<0.0001$ \\
\hline diabetes & 6.9 & 2.6 & $<0.01$ & 0.5 & 0.7 & ns \\
\hline metabolic syndrome & 2.2 & 3.9 & $\mathrm{~ns}$ & 1.4 & 2.5 & ns \\
\hline antihypertensive medication & 13.3 & 13.3 & $\mathrm{~ns}$ & 6.7 & 7.1 & $\mathrm{~ns}$ \\
\hline hypoglycemic medication & 5.3 & 1.3 & $<0.001$ & 0.2 & 0.2 & $\mathrm{~ns}$ \\
\hline stroke & 1.2 & 1.7 & $\mathrm{~ns}$ & 1.8 & 0.7 & $\mathrm{~ns}$ \\
\hline ischemic heart disease & 3.8 & 2.8 & $\mathrm{~ns}$ & 0.9 & 2.1 & ns \\
\hline current smoker & 36.2 & 32.0 & $\mathrm{~ns}$ & 6.0 & 7.3 & $\mathrm{~ns}$ \\
\hline
\end{tabular}

Table 4. Data Stratified by \% Vital Capacity $\left(\%\right.$ VC) in Men with $\mathrm{BMI}<23 \mathrm{~kg} / \mathrm{m}^{2}$ Excluding Current Smokers

\begin{tabular}{|c|c|c|c|}
\hline & $\% \mathrm{VC} \leq 95$ & $\% \mathrm{VC} \geq 96$ & $\mathrm{p}$ \\
\hline $\mathrm{n}$ & 316 & 362 & \\
\hline$\%$ vital capacity $(\%)$ & $87.2 \pm 6.4$ & $105.1 \pm 7.3$ & $<0.0001$ \\
\hline age (year) & $49.9 \pm 10.3$ & $52.5 \pm 9.2$ & $<0.001$ \\
\hline BMI $\left(\mathrm{kg} / \mathrm{m}^{2}\right)$ & $20.7 \pm 1.6$ & $21.3 \pm 1.2$ & $<0.0001$ \\
\hline body (fat \%) & $18.6 \pm 3.9$ & $19.5 \pm 3.4$ & $<0.01$ \\
\hline waist circumference $(\mathrm{cm})$ & $77.9 \pm 5.8$ & $79.5 \pm 5.1$ & $<0.001$ \\
\hline systolic blood pressure (mmHg) & $116 \pm 17$ & $121 \pm 17$ & $<0.01$ \\
\hline diastolic blood pressure (mmHg) & $74 \pm 11$ & $77 \pm 11$ & $<0.01$ \\
\hline fasting plasma glucose $(\mathrm{mg} / \mathrm{dL})$ & $93.5 \pm 14.4$ & $93.3 \pm 10.9$ & ns \\
\hline triglycerides $(\mathrm{mg} / \mathrm{dL})$ & $95.3 \pm 53.8(84)$ & $100 \pm 61(85)$ & ns \\
\hline HDL cholesterol (mg/dL) & $63.7 \pm 15.3$ & $63.7 \pm 14.2$ & ns \\
\hline high-sensitivity CRP (mg/L) & $0.44 \pm 0.83(0.22)$ & $0.35 \pm 0.54(0.19)$ & ns \\
\hline white blood cell count $\left(/ \mathrm{L}^{-6}\right)$ & $4966 \pm 1144$ & $4939 \pm 1092$ & ns \\
\hline heart rate $(/ \mathrm{min})$ & $59.1 \pm 9.3$ & $58.9 \pm 9.5$ & ns \\
\hline FEV $1 \%(\%)$ & $82.7 \pm 7.0$ & $80.1 \pm 6.1$ & $<0.0001$ \\
\hline diabetes & 5.4 & 2.2 & $<0.05$ \\
\hline metabolic syndrome & 1.3 & 3.9 & $<0.05$ \\
\hline antihypertensive medication & 14.6 & 14.4 & ns \\
\hline hypoglycemic medication & 4.1 & 1.1 & $<0.05$ \\
\hline stroke & 1.9 & 2.2 & ns \\
\hline ischemic heart disease & 4.1 & 3.0 & ns \\
\hline
\end{tabular}

positively correlated with $\% \mathrm{VC}$ in the obese men, BMI, BF $\%$, WC, SBP, DBP, and age were, unexpectedly, significantly positively and only hs-CRP and WBC were significantly negatively correlated with $\% \mathrm{VC}$ in the lean men. While WC, SBP, fasting plasma glucose, hs-CRP, WBC, and GGT were significantly negatively correlated with \%VC in the obese women, BMI, BF\%, WC, SBP, DBP, triglycerides, and age were, unexpectedly, significantly positively and only hs-CRP and heart rate were significantly negatively corre- lated with \% VC in the lean women.

\section{Discussion}

Lazarus et al found that FVC, FEV1, and maximal midexpiratory flow rate were predictors of insulin resistance (1). Engstrom and Janzon (2) reported that low FVC and FEV1 predicts diabetes independent of adiposity and that the incidence of cardiovascular disease is significantly increased 
Table 5. Data by the Quartile of \% Vital Capacity (\%VC) in Men with $\mathrm{BMI}<23 \mathrm{~kg} / \mathrm{m}^{2}$

\begin{tabular}{|c|c|c|c|c|c|}
\hline$\% \mathrm{VC}$ quartiles & $\begin{array}{c}\text { Q1 } \\
54-88 \%\end{array}$ & $\begin{array}{c}\text { Q2 } \\
89-96 \%\end{array}$ & $\begin{array}{c}\text { Q3 } \\
97-103 \%\end{array}$ & $\begin{array}{c}\text { Q4 } \\
104-142 \%\end{array}$ & $\mathrm{P}^{*}$ \\
\hline $\mathrm{n}$ & 261 & 270 & 242 & 254 & \\
\hline$\%$ vital capacity $(\%)$ & $82.9 \pm 5.1$ & $92.6 \pm 2.2$ & $100 \pm 2.0$ & $110.5 \pm 5.9$ & $<0.0001$ \\
\hline age (year) & $50.5 \pm 10.3$ & $50.1 \pm 9.1$ & $50.9 \pm 8.7$ & $52.7 \pm 8.9$ & $<0.01$ \\
\hline BMI $\left(\mathrm{kg} / \mathrm{m}^{2}\right)$ & $20.5 \pm 1.7$ & $20.9 \pm 1.4$ & $21.1 \pm 1.4$ & $21.4 \pm 1.2$ & $<0.0001$ \\
\hline body (fat \%) & $18.4 \pm 3.9$ & $18.9 \pm 3.5$ & $19.1 \pm 3.7$ & $19.5 \pm 3.5$ & $<0.01$ \\
\hline waist circumference $(\mathrm{cm})$ & $77.6 \pm 6.0$ & $78.6 \pm 5.2$ & $79.0 \pm 5.4$ & $79.7 \pm 4.8$ & $<0.0001$ \\
\hline systolic blood pressure (mmHg) & $116 \pm 17$ & $117 \pm 17$ & $119 \pm 16$ & $119.5 \pm 17$ & $<0.01$ \\
\hline diastolic blood pressure ( $\mathrm{mmHg}$ ) & $73.7 \pm 10$ & $74.3 \pm 11$ & $76 \pm 10$ & $76 \pm 10$ & $<0.01$ \\
\hline fasting plasma glucose $(\mathrm{mg} / \mathrm{dL})$ & $96.2 \pm 19.0$ & $93.7 \pm 17.3$ & $92.9 \pm 10.7$ & $92.6 \pm 10.2$ & $<0.01$ \\
\hline triglycerides $(\mathrm{mg} / \mathrm{dL})$ & $99.5 \pm 54.3(87)$ & $103 \pm 67.4(88.5)$ & $106 \pm 64.8(89.5)$ & $99.2 \pm 54.8(86)$ & $\mathrm{ns}$ \\
\hline HDL cholesterol (mg/dL) & $61.6 \pm 16.4$ & $62.9 \pm 15.0$ & $61.5 \pm 13.9$ & $63.5 \pm 14.6$ & ns \\
\hline high-sensitivity CRP (mg/L) & $0.57 \pm 1.01(0.26)$ & $0.38 \pm 0.53(0.23)$ & $0.48 \pm 0.93(0.22)$ & $0.44 \pm 0.88(0.20)$ & ns \\
\hline white blood cell count $\left(/ \mathrm{L}^{-6}\right)$ & $5486 \pm 1523$ & $5196 \pm 1276$ & $5407 \pm 1454$ & $5239 \pm 1509$ & ns \\
\hline heart rate $(/ \mathrm{min})$ & $59.4 \pm 9.2$ & $58.9 \pm 9.1$ & $58.3 \pm 9.0$ & $58.8 \pm 9.0$ & ns \\
\hline FEV $1 \%(\%)$ & $81.2 \pm 8.5$ & $81.3 \pm 6.0$ & $80.5 \pm 5.8$ & $78.6 \pm 5.9$ & $<0.0001$ \\
\hline diabetes & 8.4 & 5.2 & 2.9 & 2.0 & $<0.01$ \\
\hline metabolic syndrome & 3.4 & 1.1 & 5.0 & 3.1 & $\mathrm{~ns}$ \\
\hline antihypertensive medication & 15.3 & 10.7 & 12.8 & 14.6 & $\mathrm{~ns}$ \\
\hline hypoglycemic medication & 7.3 & 3.0 & 1.2 & 1.2 & $<0.001$ \\
\hline stroke & 1.9 & 0.4 & 1.2 & 2.4 & $\mathrm{~ns}$ \\
\hline ischemic heart disease & 5.4 & 1.9 & 4.1 & 2.0 & $<0.05$ \\
\hline current smoker & 37.9 & 34.4 & 35.1 & 28.3 & $<0.05$ \\
\hline
\end{tabular}

Data are mean \pm SD (median) or percent. "P values are comparisons between Q1 and Q4. Abbreviations are the same as in Table 1.

Table 6. Spearman's Correlation Coefficients between \% Vital Capacity and Metabolic Risk Factors

\begin{tabular}{|c|c|c|c|c|c|c|c|c|}
\hline & \multicolumn{4}{|c|}{ men } & \multicolumn{4}{|c|}{ women } \\
\hline & \multicolumn{2}{|c|}{$\mathrm{BMI}<23$} & \multicolumn{2}{|c|}{$\mathrm{BMI} \geq 23$} & \multicolumn{2}{|c|}{$\mathrm{BMI}<23$} & \multicolumn{2}{|c|}{$\mathrm{BMI} \geq 23$} \\
\hline & $\mathrm{r}$ & $\mathrm{p}$ & $\mathrm{r}$ & $\mathrm{p}$ & $\mathrm{r}$ & $\mathrm{p}$ & $\mathrm{r}$ & $\mathrm{p}$ \\
\hline $\mathrm{n}$ & \multicolumn{2}{|c|}{1027} & \multicolumn{2}{|c|}{1052} & \multicolumn{2}{|c|}{872} & \multicolumn{2}{|c|}{343} \\
\hline age & 0.094 & $<0.01$ & -0.006 & ns & 0.148 & $<0.0001$ & -0.079 & $\mathrm{~ns}$ \\
\hline BMI & 0.210 & $<0.0001$ & -0.141 & $<0.0001$ & 0.270 & $<0.0001$ & -0.073 & $\mathrm{~ns}$ \\
\hline body fat $\%$ & 0.104 & $<0.001$ & -0.198 & $<0.0001$ & 0.134 & $<0.0001$ & -0.098 & ns \\
\hline waist circumference & 0.132 & $<0.0001$ & -0.144 & $<0.0001$ & 0.180 & $<0.0001$ & -0.157 & $<0.01$ \\
\hline systolic blood pressure & 0.104 & $<0.001$ & -0.083 & $<0.01$ & 0.083 & $<0.05$ & -0.155 & $<0.01$ \\
\hline diastolic blood pressure & 0.094 & $<0.01$ & -0.067 & $<0.05$ & 0.085 & $<0.05$ & -0.122 & $<0.05$ \\
\hline fasting plasma glucose & 0.011 & $\mathrm{~ns}$ & -0.100 & $<0.01$ & 0.065 & ns & -0.205 & $<0.001$ \\
\hline triglycerides & -0.004 & ns & -0.146 & $<0.0001$ & 0.076 & $<0.05$ & -0.053 & ns \\
\hline HDL cholesterol & 0.059 & ns & 0.171 & $<0.0001$ & -0.049 & ns & 0.055 & ns \\
\hline high-sensitivity CRP & -0.098 & $<0.01$ & -0.189 & $<0.0001$ & -0.074 & $<0.05$ & -0.166 & $<0.01$ \\
\hline white blood cell count & -0.065 & $<0.05$ & -0.133 & $<0.0001$ & -0.010 & ns & -0.132 & $<0.05$ \\
\hline gamma glutamyltransferase & 0.010 & ns & -0.105 & $<0.001$ & 0.024 & ns & -0.117 & $<0.05$ \\
\hline heart rate & -0.05 & ns & -0.057 & $\mathrm{~ns}$ & -0.069 & $<0.05$ & -0.005 & ns \\
\hline
\end{tabular}

r: Spearman's correlation coefficients. Other abbreviations are the same as in Table 1.

among subjects with low \%VC who developed insulin resistance (Engstrom et al, 3). Ford and Mannino found that restrictive lung disease is significantly associated with the incidence of diabetes but not obstructive lung disease (4). Yeh et al also concluded that lower vital capacity predicts the development of diabetes and that the association between respiratory function and diabetes is stronger in never smokers and it appears to be specific to vital capacity, since FEV1\% was not at all related to diabetic risk and that the subjects with lower vital capacity had many features of MS or insulin resistance at baseline (5). There are a few cross-sectional studies on the association between respiratory function and metabolic risk factors in Japanese $(8,9)$. Previously, we found that $\% \mathrm{VC}$ is significantly lower in MS subjects than in non-MS subjects in Japanese men, but not in women and the prevalence of MS and diabetes is significantly higher in Q1 than in Q4 in Japanese men, but not in women (10). We thought that the number of subjects with diabetes was too small to detect a statistical significance in women and paradoxically positive correlations between $\% \mathrm{VC}$ and obesity parameters in women might result from the leanness rather than obesity in Japanese women.

In the present study, we examined cross-sectional relationships between \%VC and diabetes and MS-related risk factors separately in the lean subjects and the obese subjects. The relationships between \%VC and diabetes and MSrelated risk factors were in accord with the previous reports (1-5) in both the obese men and women. In the lean men, the prevalence of diabetes, but not MS, was significantly higher in subjects with the lower \%VC than in those with 
the higher \%VC despite the fact that age, BMI, BF\%, WC, SBP, and DBP were significantly lower in subjects with the lower \% VC than in those with the higher \% VC and triglycerides, HDL cholesterol, hs-CRP, WBC, and heart rate were not significantly different in the two groups. In the lean women, the prevalence of diabetes was not significantly different between subjects with the lower \%VC and those with the higher \% VC and the results were essentially the same after excluding current smokers (data not shown). But, the result was not conclusive because the number of diabetic subjects in the lean women was only 5 . In Tables 3, 4, fasting plasma glucose was not significantly different between men with lower vital capacity and men with higher vital capacity. The reason may be the small sample size insufficient to detect statistically significant differences and the confounding effect of hypoglycemic medication because fasting plasma glucose is significantly higher in Q1 than in Q4 in Table 5.

The underlying mechanisms linking low vital capacity and diabetes in lean men are not clear. MS-related risk factors were inversely related with reduced $\% \mathrm{VC}$ in lean men and the prevalence of MS was significantly lower in subjects with the lower \%VC than those with the higher \%VC when current smokers were excluded. It is possible that unknown mechanisms different from insulin resistance is involved. Decreased insulin secreting capacity (11) rather than insulin resistance (12) or a simple genetic linkage may be a possible link. Reduced vital capacity in lean men may be a result of diabetes $(13,14)$, not a predictor of diabetes. However,
hs-CRP and WBC were significantly negatively correlated with \%VC even in lean men. Therefore, inflammation, which is closely linked to insulin resistance (15-17), may be involved in the association between vital capacity and diabetes even in lean men.

\section{Limitations}

Regrettably, we did not measure insulin levels. We are planning the next study to detect whether the relationship between vital capacity and insulin secreting function or insulin resistance is different between lean and obese diabetic men. If the relationship is similar between lean and obese diabetic men, then, it means that insulin resistance dissociates from metabolic syndrome in lean diabetic men. If lower vital capacity is associated with lower insulin secreting capacity in lean diabetic men, then, there may be some common mechanisms between insulin secreting capacity of pancreatic beta-cells and vital capacity which may be related to the surfactant protein secreting capacity of pulmonary alveolar cells (18) or contractile strength of respiratory muscles (19).

\section{Acknowledgement}

We thank all subjects who participated in the study, the staff at our Medical Check-up Center who assisted the study, and Drs. Shinzo Tachikawa, Shinpei Yoshii and Masaaki Okabe at Tachikawa Medical Center for their effort to construct the study environment.

\section{References}

1. Lazarus R, Sparrow D, Weiss ST. Baseline ventilator function predicts the development of higher levels of fasting insulin and fasting insulin resistance index: the Normative Aging Study. Eur Respir J 12: 641-645, 1998.

2. Engstrom G, Janzon L. Risk of developing diabetes is inversely related to lung function: a population-based cohort study. Diabet Med 19: 167-170, 2002.

3. Engstrom G, Hedblad B, Nilsson P, Wollmer P, Berglund G, Janzon L. Lung function, insulin resistance and incidence of cardiovascular disease: a longitudinal cohort study. J Intern Med 253: 574-581, 2003.

4. Ford ES, Mannino DM. Prospective association between lung function and the incidence of diabetes. Findings from the National Health and Nutrition Examination Survey Epidemiologic Followup Study. Diabetes Care 27: 2966-2970, 2004.

5. Yeh H, Punjabi NM, Wang N, Pankow JS, Duncan BB, Brancati FL. Vital capacity as a predictor of incident type 2 diabetes. The Atherosclerosis Risk in Communities Study. Diabetes Care 28: 1472-1479, 2005.

6. Grundy SM, Cleeman JI, Daniels SR, et al. Diagnosis and management of the metabolic syndrome: a statement for health care professionals: an American Heart Association/National Heart, Lung, and Blood Institute Scientific Statement. Circulation 112: 2735-2752, 2005.

7. Alverti KGMM, Zimmet P, Shaw J. Metabolic syndrome-a new world-wide definition. A consensus statement from the International Diabetes Federation. Diabet Med 23: 469-480, 2006.

8. Nakajima K, Kubouchi Y, Muneyuki T, Ebata M, Eguchi S, Mu- nakata H. A possible association between suspected restrictive pattern as assessed by ordinary pulmonary function test and the metabolic syndrome. Chest 134: 712-718, 2008.

9. Sakuta H, Suzuki T, Yasuda H, Ito T. Vital capacity and selected metabolic diseases in middle-aged Japanese men. Can Resp J 13: 79-82, 2006.

10. Oda E, Kawai R. A cross-sectional relationship between vital capacity and diabetes in Japanese men. Diabetes Res Clin Pract 85: 111-116, 2009.

11. Gerich JE. Contribution of insulin-resistance and insulin-secretory defects to the pathogenesis of type 2 diabetes mellitus. Mayo Clin Proc 78: 447-456, 2003.

12. Reaven GM. Role of insulin resistance in human disease. Diabetes 37: 1595-1607, 1988.

13. Chance WW, Rhee $\mathrm{C}$, Yilmaz $\mathrm{C}$, et al. Diminished alveolar microvascular reserves in type 2 diabetes reflect systemic microangiopathy. Diabetes Care 31: 1596-1601, 2008.

14. Yeh H, Punjabi NM, Wang N, et al. Cross-sectional and prospective study of lung function in adults with type 2 diabetes. Diabetes Care 31: 741-746, 2008.

15. Dandona P, Aljada A, Chaudhuri A, Mohanty P, Garg R. Metabolic syndrome: a comprehensive perspective based on interactions between obesity, diabetes, and inflammation. Circulation 2005; 111: 1448-1454, 2005.

16. Kim J, Montagnani M, Koh KK, Quon MJ. Reciprocal relationships between insulin resistance and endothelial dysfunction: molecular and pathophysiological mechanisms. Circulation 113: 1888-1904, 2006. 
17. Oda E. The metabolic syndrome as a concept of adipose tissue disease. Hypertens Res 31: 1285-1293, 2008.

18. Fernandez-Real JM, Chico B, Shiratori M, Nara Y, Takahashi H, Ricart W. Circulating surfactant protein A (SP-A), a marker of lung injury, is associated with insulin resistance. Diabetes Care 31: 958-963, 2008.
19. Harita N, Hayashi T, Kogawa-Sato K, Nakamura Y, Yoneda T, Endo G. Lower serum creatinine is a new risk factor of type 2 diabetes: The Kansai Healthcare Study. Diabetes Care 32: 424426, 2009.

(C) 2009 The Japanese Society of Internal Medicine
http://www.naika.or.jp/imindex.html 